\title{
A Scoping Review on Nutrition Challenges Among People Living With HIV/AIDS in Sub-Saharan Africa
}

\author{
Tafadzwa Dzinamarira ${ }^{1}$, Gashema Pierre ${ }^{2}$, Itai Chitungo ${ }^{3}$, Michael Habtu ${ }^{1} \&$ Rosemary Okova ${ }^{1}$ \\ ${ }^{1}$ Department of Public Health, Mount Kenya University, Kigali, Rwanda \\ ${ }^{2}$ College of Medicine and Health Sciences, University of Rwanda, Kigali, Rwanda \\ ${ }^{3}$ Department of Medical Laboratory Sciences, University of Zimbabwe, Harare, Zimbabwe \\ Correspondence: Tafadzwa Dzinamarira, Department of Public Health, Mount Kenya University, Kigali, Rwanda.
}

Received: August 28, 2019 Accepted: September 25, 2019 Online Published: October 9, 2019

doi:10.5539/gjhs.v11n12p109 URL: https://doi.org/10.5539/gjhs.v11n12p109

\begin{abstract}
The connection between under-nutrition and HIV is bidirectional. It affects the quality of life, as well as the survival of affected people. While this is the case, there are various nutritional challenges, which are faced by people living with HIV/AIDS (PLWH), and which hamper the fight against the scourge. This study therefore sought to map literature on the nutritional challenges among PLWH in sub-Saharan Africa and guide future research in nutritional management to improve health outcomes for PLWH. A systematic search was done from the following sources: PubMed, the Cochrane Database of Systematic Reviews, EBSCOhost (CINAHL and Academic Search Complete), Web of Science, and Google Scholar. In addition, information was obtained both from unpublished studies, which included book chapters, reference lists, theses and conference papers. Eleven (11) studies met the inclusion criteria, and were used for data extraction. The studies were based in different countries, which form part of the Sub Saharan Africa. One of the studies was carried out in Senegal, two studies were carried out in various West African countries, one study was carried out in Burkina Faso; one study was carried out in Ethiopia and one of the studies was carried out in different countries forming part of the Sub Saharan Africa. Two of the studies were carried out in Zambia, one in Zimbabwe, one in Cameroon, and one in Ghana. Most of the studies established the main nutrition challenge facing PLWH to be food insecurity. Based on the findings of the study, it can be concluded that some of the main nutrition challenges include food insecurity, lack of nutritional support among PLWH, late detection of HIV, huge cost of treating severe acute malnutrition, and lack of feeding supplementations.
\end{abstract}

Keywords: Nutrition challenges, People living with HIV, Sub-Saharan Africa

\section{Abbreviations}

ART: Antiretroviral therapy

HAART: Highly active antiretroviral therapy

PLWH: People living with HIV/AIDS

\section{Background}

Over 37 million individuals are living with HIV across the globe as of 2017 (WHO, 2018). Despite the fact that there has been a drastic decline in the number of new infections, there has been a rapid increase in the number of individuals living with HIV (Kharsany \& Karim, 2016; WHO, 2018). This can be attributed to the fact that the people are living longer and healthier lives because of effective antiretroviral therapy (ART). When taken in the prescribed manner, ART significantly reduces viral load besides facilitating immune reconstitution (Cloete et al., 2010; Ensoli, Cafaro, Monini, Marcotullio, \& Ensoli, 2014; Karim, 2017). Good nutritional status is also highly significant for individuals who are infected with HIV. It is worth pointing out that the HIV always attacks individuals' immune system (Mbirimtengerenji, 2007). During the early phases of infection, individuals demonstrate no visible signs of illness. While good nutrition is key for people living with HIV/AIDS (PLWH), there are challenges, which are still being experienced. This study therefore sought to map evidence on the nutritional challenges faced by PLWH in sub-Saharan Africa to guide future research in nutrition and HIV/AIDS.

HIV/AIDS epidemic has huge effects on human and economic development, nutritional status and food security, 
majorly within the poor communities, and most noticeably in the sub-Saharan Africa (Almeida-Brasil et al., 2018). At household level, HIV/AIDS may have a highly disastrous impact on food security and nutrition (Ivers et al., 2009). HIV affects more individuals than it infects. Every dimension of food security, like availability of food, access and use, are always at risk within the environments in which there is a high HIV/AIDS prevalence (Badri et al., 2005; Bigna, Plottel, \& Koulla-Shiro, 2016). Therefore, finding lasting solutions to the different nutritional challenges among PLWH is highly beneficial in ensuring that the adverse impacts, which are associated with the HIV/AIDS epidemic are avoided.

Lack of proper nutrition makes PLWH not to be in a position to maintain healthy and high quality life. Given infection with HIV to a great extent damages a person's immune system, this result in other kinds of infections, like diarrhea and fever (Alebel et al., 2018; Berhe, Tegabu, \& Alemayehu, 2013) which have a ripple effect of lowering intake of food and interfering with the ability of the body to absorb food. Therefore, the given individual is weakened, becomes malnourished, and loses weight (Alebel et al., 2018; Duggal, Chugh, \& Duggal, 2012; Elfstrand \& Florén, 2010). Nutritional support and care are the integral components of any action taken. While there are a number of benefits, which are linked to proper nutrition for the PLWH, in the sub-Saharan Africa, a number of challenges are faced, which result in malnutrition among PLWH (Duggal et al., 2012; Loos et al., 2017). At the time of the review, there was no existing published synthesis on the nutrition challenges among PLWH in sub-Saharan Africa. Our research question was what evidence is available on nutritional challenges among PLWH in sub-Saharan Africa.

\section{Methods}

The Arksey and O'Malley's 2005 scoping methodological framework (Arksey \& O'Malley, 2005) guided this review. A three-step process was followed. The protocol for the scoping review is published elsewhere (Dzinamarira \& Mashora, 2019). First was article search using keywords as detailed in Table 1. Thereafter all eligible references were imported to EndNote X9 software. Duplicates were removed. This was followed by a title screen. Next, we performed abstract screen for eligibility. Articles that met the criteria detailed in Table 2 underwent full title review for eligibility. Extraction of data took place after this, and analysis of the results was done through the use of qualitative thematic analysis. We employed NVivo version 12 to analyze and code the data. A scoping review protocol was developed priori (Dzinamarira \& Mashora, 2019) but was not registered on PROSPERO as PROSPERO currently does not accept scoping review protocols. The protocol was guided by Preferred Reporting Items for systematic review and meta-analysis protocols (PRISMA-P) 2015 guidelines.

Table 1. Results from keyword search

\begin{tabular}{|c|c|c|c|}
\hline Keywords Search & $\begin{array}{l}\text { Date of } \\
\text { Search }\end{array}$ & $\begin{array}{c}\text { Search Engine } \\
\text { Used }\end{array}$ & $\begin{array}{c}\text { Number of } \\
\text { publications } \\
\text { retrieved }\end{array}$ \\
\hline $\begin{array}{l}\text { (("nutritional status"[MeSH Terms] OR ("nutritional"[All Fields] AND } \\
\text { "status"[All Fields]) OR "nutritional status"[All Fields] } \\
\text { "nutrition"[All Fields] OR "nutritional sciences"[MeSH Terms] OR } \\
\text { ("nutritional"[All Fields] AND "sciences"[All Fields]) OR "nutritional } \\
\text { sciences"[All Fields]) AND ("Plan Parent Chall"[Journal] OR } \\
\text { "challenges"[All Fields])) AND (("persons"[MeSH Terms] OR } \\
\text { "persons"[All Fields] OR "people"[All Fields]) AND living[All Fields] } \\
\text { AND ("hiv"[MeSH Terms] OR "hiv"[All Fields]) AND ("africa south of } \\
\text { the sahara"[MeSH Terms] OR ("africa"[All Fields] AND "south"[All } \\
\text { Fields] AND "sahara"[All Fields]) OR "africa south of the sahara"[All } \\
\text { Fields] OR ("sub"[All Fields] AND "saharan"[All Fields] AND } \\
\text { "africa"[All Fields]) OR "sub saharan africa"[All Fields])) AND } \\
\text { ("2001/01/01"[PDAT]: "2019/01/31"[PDAT]) }\end{array}$ & $2 / 11 / 2019$ & PubMed & 23 \\
\hline $\begin{array}{l}\text { ((sub[All Fields] AND Saharan[All Fields] AND ("Africa"[MeSH } \\
\text { Terms] OR "nutrition"[All Fields]) AND challenge[All Fields]) AND } \\
\text { ("people"[MeSH Terms] OR "living"[All Fields])) AND } \\
\text { (("with"[MeSH Terms] OR ("HIV"[All Fields] AND "AIDS"[All } \\
\text { Fields]) }\end{array}$ & $2 / 11 / 2019$ & Google Scholar & 949 \\
\hline
\end{tabular}




\begin{tabular}{|c|c|c|c|}
\hline $\begin{array}{l}\text { Nutrition AND people living with HIV [MeSH Terms }] \text { AND } \\
\text { sub-Saharan Africa }\end{array}$ & $2 / 11 / 2019$ & $\begin{array}{l}\text { Cochrane } \\
\text { database of } \\
\text { systematic } \\
\text { reviews }\end{array}$ & 29 \\
\hline $\begin{array}{l}\text { sub AND Saharan AND "Africa" AND "nutrition" OR "nutritional } \\
\text { challenges" AND people living OR "HIV/AIDS" }\end{array}$ & $2 / 14 / 2019$ & $\begin{array}{l}\text { EBSCOhost } \\
\text { (CINAHL and } \\
\text { Academic } \\
\text { Search } \\
\text { Complete) }\end{array}$ & 236 \\
\hline $\begin{array}{l}\text { sub AND Saharan AND "Africa" AND "nutrition" OR "nutritional } \\
\text { challenges" AND people living OR "HIV/AIDS" }\end{array}$ & $2 / 14 / 2019$ & Web of Science & 1,320 \\
\hline Total articles from primary search & & & 2,557 \\
\hline
\end{tabular}

Table 2. Tool used to screen abstracts and review full text articles

\begin{tabular}{ll}
\hline Abstract Screening and Full text review Tool & \\
\hline Author and publication date & (Yes/No) \\
Title of article & (Yes/No) \\
Does this article include evidence from sub-Saharan Africa? & (Yes/No) \\
Does this article include evidence on people living with HIV/AIDS? & \\
Does this article provide evidence nutrition challenges among people living with HIV/AIDS? &
\end{tabular}

\subsection{Study Design}

The study adopted qualitative scoping review design. A scoping review has been shown to map literature on a given topic or on a given research area (Pham et al., 2014). Scoping reviews offer chance for the identification of the key concepts, research gaps and the kinds and sources of evidence with the aim of informing practice, policymaking, as well as research (Pham et al., 2014).

\subsection{Literature Search}

A systematic search was done from the following sources: PubMed, the Cochrane Database of Systematic Reviews, EBSCOhost (CINAHL and Academic Search Complete), Web of Science, and Google Scholar. In addition, information was obtained both from unpublished studies, which included book chapters, reference lists, theses and conference papers. We considered articles published from January 2001 to January 2019.

\subsection{Inclusion Criteria}

1. Article reporting evidence on nutrition challenges among PLWH

2. The context of the article must be on sub-Saharan Africa

3. Evidence published from January 2001 to January 2019

\subsection{Exclusion Criteria}

1. Articles not focused on PLWH

2. Studies carried out in other countries other than Sub-Saharan Africa

3. Articles not having information concerning HIV/AIDS and nutrition challenges

4. Evidence published before January 2001 or after January 2019

\subsection{Study Selection}

A thorough review was done to ensure that included studies met all the aspects in the inclusion criteria. The main keywords, which were used for the search were: nutrition challenges, People living with HIV and Sub-Saharan Africa. Detailed information on searches is available on Table 1.

\subsection{Data Extraction}

Extraction of data took place through the use of a standardized data extraction form. The data that were extracted 
include: the author name, the publication year of the article, the geographical area of the studies, and research design. Characteristics of the included studies are detailed in Table 3.

Table 3. Characteristics of the studies included

\begin{tabular}{lll}
\hline Author and Date & Geographical area & Design \\
\hline Benzekri, N. A., Sambou, J., Diaw, B., et al., 2015 & Senegal & Cross-sectional study \\
\hline Jesson, J., Masson, D., Adonon, A., et al., 2011 & $\begin{array}{l}\text { Central and west } \\
\text { Africa }\end{array}$ & Cross sectional study design \\
\hline Poda, G. G., Hsu, C. Y., \& Chao, J. C., 2017 & Burkina Faso & Case-control study \\
\hline Trehan, I., O'Hare, B. A., Phiri, A., \& Heikens, G. T., 2012 & Sub Saharan Africa & Review \\
\hline $\begin{array}{l}\text { Gebremichael, D. Y., Hadush, K. T., Kebede, E. M., \& Zegeye, R. T., } \\
2018\end{array}$ & Ethiopia & Cross-sectional study \\
\hline Moramarco, S., Amerio, G., Ciarlantini, C., et al., 2016 & Cross-sectional study \\
\hline $\begin{array}{l}\text { Moyo, N., Maharaj, P., \& Mambondiani, L. 2017 } \\
\text { Benzekri, N. A., Sambou, J., Diaw, B., et al., 2015 }\end{array}$ & Zimbabwe & Cross-sectional study \\
\hline Amadi, B., Kelly, P., Mwiya, M., et al., 2001 & West Africa & Face to face in-depth interviews \\
\hline $\begin{array}{l}\text { Penda, C. I., Moukoko, E. C. E., Nolla, N. P., Evindi, N. O. A., \& } \\
\text { Ndombo, P. K., 2018 }\end{array}$ & Cameroon & Cross sectional design \\
\hline Asafo-Agyei, S. B., Antwi, S., \& Nguah, S. B., 2013 & Cross sectional design \\
\hline
\end{tabular}

\subsection{Quality Assessment}

The 2018 version of the Mixed Methods Appraisal Tool (MMAT) was used for the evaluation of the risk of bias for the studies, which were included in the review (Hong et al., 2019). The studies, which met the inclusion criteria were assessed based on a number of areas, which include: clarity of the question and research objectives; capacity of the data collected to meet the research questions; data collection from sources that are highly suitable; and rigor and appropriateness of the tool used to analyze the data. Assessment was also done based on accuracy of the sampling technique used; representativeness of the population; rate of response; and the research conclusions. Calculation of the overall percentage quality score was done for the included studies. The scores ranged from $\leq 50 \%$, which was regarded as low quality, $51-75 \%$, which was of average quality, and $76-100 \%$, which was regarded to be of high quality.

\subsection{Collating, Summarizing and Reporting the Results}

The research used thematic analysis for reporting the research findings from the existing literature. The researcher coded the evidence reported in the included articles. NVivo version 12 was employed for data management. Structuring of the literature was done based on the themes which were derived from the study outcomes.

\section{Results}

\subsection{Screening Results}

Initial search yielded 2,557 articles. Of the total, 1,437 articles remained after duplicates were removed. Further 1,171 were excluded after screening titles and 232 articles were excluded after screening abstracts. This left 23 articles for full text review (Supplementary File 1). Of these, only 11 articles met all the inclusion criteria. A detailed PRISMA flow chat is available on Figure 1. 


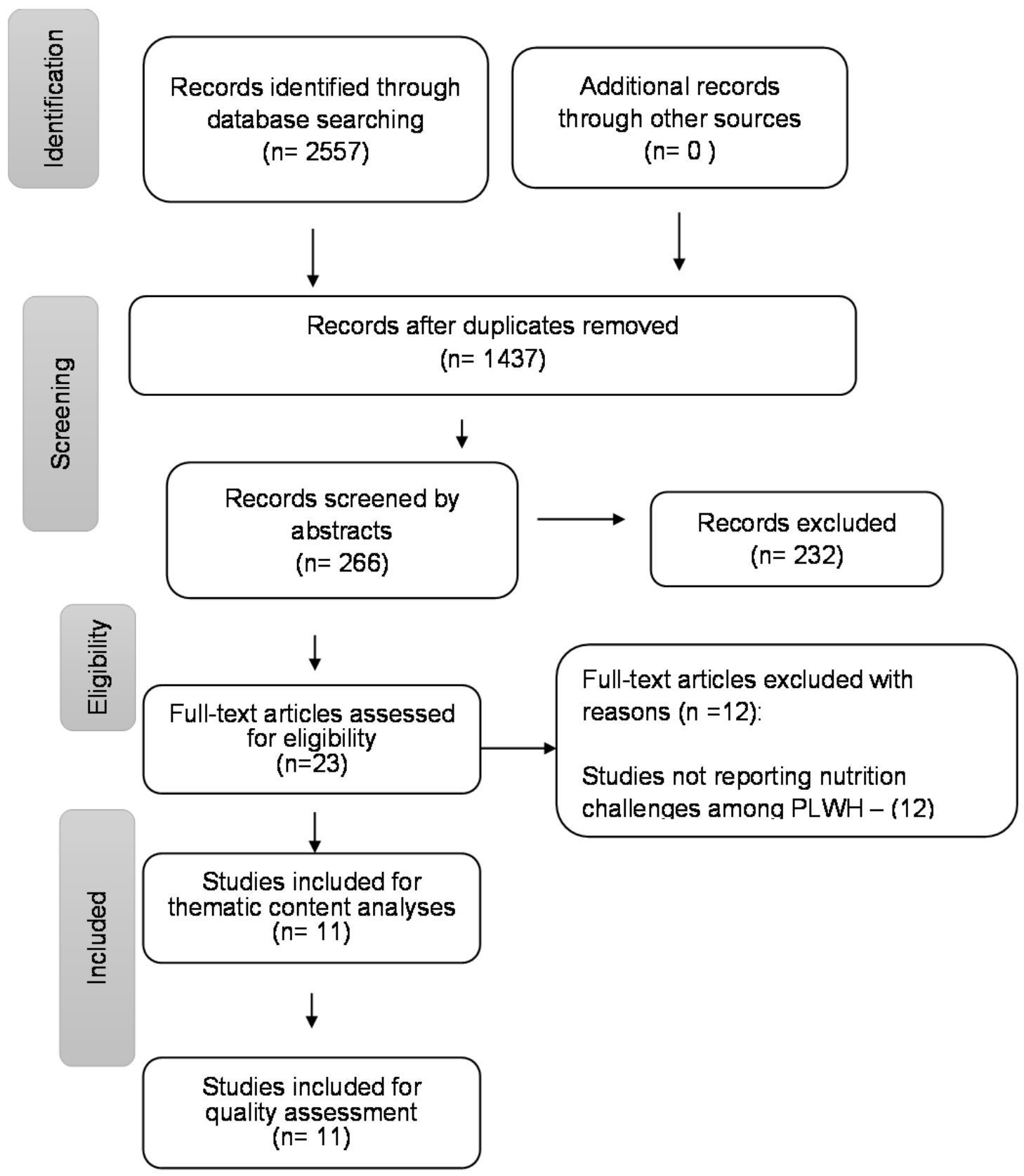

Figure 1. PRISMA Flow Chart

\subsection{Level of Bias for Included Studies}

All the included studies passed through the methodological quality assessment, which was done through the use of the Mixed Methods Appraisal tool (MMAT)-Version 2018. All studies had a score of between $40 \%$ and $100 \%$.

\subsection{Characteristics of Included Studies}

Eleven (11) studies met the inclusion criteria, and were used for data extraction. The studies were based in different countries, which form part of the Sub Saharan Africa. One of the studies was carried out in Senegal, two studies were carried out in various West African countries, one study was carried out in Burkina Faso; one study was carried out in Ethiopia and one of the studies was carried out in different countries forming part of the Sub Saharan Africa. Two of the studies, which were included, were carried out in Zambia, one in Zimbabwe, one in Cameroon, and one in Ghana. All the studies, which were included in the review, were published between the year 2001 and 2018. 


\subsection{Study Findings}

All the studies strived to provide information concerning some of the main nutrition challenges among PLWH in sub-Saharan Africa. For purposes of the review the term Nutrition - refers to the sum of all the processes, which are often involved during the intake, assimilation, and use of proper quantities of nutrients for maintaining health, productivity and well-being.

Here we present our findings in three main themes that emerged from qualitative content analysis of the included studies' findings.

\subsubsection{Food Insecurity}

Severe food insecurity is one of the leading nutrition challenges among PLWH (Benzekri et al., 2015). In their study, Benzekri et al., 2015, majority of the research participants who were HIV positive reduced their meal size due to food insecurity. The scholars linked severe food insecurity to lower dietary diversity, less education, and lower daily expenditure on household food. The study concluded by pointing out that the vast majority of HIV-infected adults in Ziguinchor and Dakar suffer from severe food insecurity. Similarly, Poda et al., 2017 also noted that food insecurity is the major challenge among PLWH in Sub-Saharan Africa (Poda, Hsu, \& Chao, 2017). This has resulted in inadequate diet (Poda et al., 2017).

Trehan et al., 2012, also cited food insecurity as one of the main nutrition challenge among children living with HIV (Trehan, O'Hare, Phiri, \& Heikens, 2012). Findings from their study showed that severely malnourished children were mainly admitted during the periods of food insecurity or during the post-weaning period. At the same time, the study noted that the other challenge is the fact that WHO's guidelines for the management of children who are hospitalized with severe malnutrition offer minimal specific assistance for treating malnourished children having HIV (Trehan et al., 2012). In Zimbabwe, Moyo et al., 2017, also indicated that one of the main changes, which is always faced include food insecurity, which were disguised as economic factors and inadequate rainfall (Moyo, Maharaj, \& Mambondiani, 2017). According to Moyo et al. 2017, this has posed huge challenges to the ability of the HIV/AIDS patients to maintain a healthy diet. A sub-theme that emerged from findings of this study was reliance on processed foods, which are less healthy rather than on indigenous foods. Earlier work by Benzekri et al., 2015 in Senegal yielded similar findings (Benzekri et al., 2015).

\subsubsection{Lack of Nutritional Support}

Another important theme that emerged from work carried out by Jesson et al., 2015, indicated that lack of nutritional support was an important challenge among PLWH in sub-Saharan Africa (Jesson et al., 2015). The findings pointed out that among the malnourished children, over half of them did not receive any kind of nutritional support.

\subsubsection{Limited Resources and Lack of Feeding Supplementation}

In Ethiopia, Gebremichael et al., 2018, reported limitedness of resources as a main challenge (Gebremichael, Hadush, Kebede, \& Zegeye, 2018). HIV/AIDS patients to lack access to adequate nutritious foods (Gebremichael et al., 2018). This poses a huge challenge to the success of ART. Moramarco et al., 2016 went further to add late detection of HIV/AIDS and lack of feeding supplementation as key nutritional challenges among PLWH in Zambia (Moramarco et al., 2016). Late detection of HIV and malnutrition as well as concomitant inadequate nutrition were also reported as the main nutrition challenge among PLWH (Amadi et al., 2001).

Evidence of proxy indicators to nutrition challenges were presented in a sub-theme; inaccessibility of appropriate and timely medical services.

\subsection{Inaccessibility of Appropriate and Timely Medical Services}

The findings from Penda et al., 2018, indicated that one of the main contributions to the excess mortality because of malnutrition among HIV-positive children is inaccessibility of appropriate and timely medical services (Penda, Moukoko, Nolla, Evindi, \& Ndombo, 2018). It noted the numerous barriers to access of medical care. The findings also indicated that the main financial barrier to treatment for both HIV as well as malnutrition is the huge cost of medical treatment in the nations in which public healthcare is not available. The scholars also noted that co-infection is another significant contributor to severe acute malnutrition among HIV-positive children. They noted that efforts to minimize the number of infections, like gastroenteritis (eg, through water sanitation), are highly significant. In Ghana, Asafo-Agyei et al., 2013, noted a high HIV seroprevalence among children with severe acute malnutrition and a significantly poorer outcome in mortality as well as weight gain (Asafo-Agyei, Antwi, \& Nguah, 2013). 


\section{Discussion}

The scoping review has mapped available literature on the nutrition challenges facing PLWH in sub Saharan Africa. The findings of the studies indicate that the notable nutritional challenges facing PLWH in sub Saharan Africa include food insecurity, huge cost of treating malnutrition, lack of nutritional support, and lack of feeding supplements.

Nutrition is essential when it comes to the HIV morbidity and mortality. Improved treatment modalities play a highly significant role in increasing life expectancy of HIV-infected individuals. Over 1 million adults within the United States live with HIV (Thuppal, Jun, Cowan, \& Bailey, 2017). A study was carried out in Kathmandu Valley, Nepal with the aim of estimating the prevalence of under-nutrition among PLWH in Nepal, and also to point out the main risk factors and to evaluate the correlations with PLWHs' quality of life and nutritional status (Thapa, Amatya, Pahari, Bam, \& Newman, 2015). Based on the findings of the research, some of the main nutritional challenges, which are faced, include illiteracy, and residence in care homes.

The usage of dietary supplements is very common among PLWH. The main challenges, which are always faced, include vulnerability of individuals to medical misinformation as well as to unfounded health claims (Evans et al., 2013; Kalichman et al., 2012; Mothi, Karpagam, Swamy, Mamatha, \& Sarvode, 2011). The findings of our scoping review generally indicate that some of the nutritional challenges are common across borders. As a result, various measures can be put in place to ensure that the challenges are addressed effectively and efficiently.

Consistent with our findings, Weiser et al. noted that food insecurity is a major risk factor for mortality among the antiretroviral therapy-treated individuals in British Columbia, mainly among the people who are underweight (Weiser et al., 2009; Weiser et al., 2011). Innovative approaches for addressing food insecurity ought to be included in the HIV treatment programs. HIV-positive Injection Drug Users (IDU) reporting food insecurity are almost twice as likely to die, in comparison to food secure IDU (Anema, Vogenthaler, Frongillo, Kadiyala, \& Weiser, 2009). The scholars therefore recommended the need for public health organizations to evaluate the possible role that food supplementation as well as socio-structural supports for IDU can play in reducing harm (Anema et al., 2009).

Our findings revealed lack of nutritional support and limited resources to contribute to nutritional challenges among PLWH in sub-Saharan Africa. Earlier work by Hailemariam et al., 2013, identified unemployment, one \& more number of previous opportunistic infections as well as gastrointestinal symptoms to be risk factors for malnutrition among PLWH (Hailemariam, Bune, \& Ayele, 2013). The scholars therefore recommended various nutritional programs to be an integral component of HIV/AIDS continuum of care (Hailemariam et al., 2013).

\section{Implications for Practice}

Nutritional challenges have become a major concern, and measures need to be put in place to ensure that the right strategies are adopted in order to deal with the nutritional challenges among PLWH. The findings of this study indicates that the main nutrition challenges include food insecurity, lack of nutritional support among PLWH, and lack of feeding supplementations. Practitioners need to ensure that adequate health education on nutrition is provided to PLWH.

\section{Implications for Research}

Progress has been made in HIV epidemic control in sub-Saharan Africa with some countries reported to be nearing epidemic control for HIV. This has brought a shift in focus to ensuring quality life for PLWH. This study guides future research in nutritional management to improve health outcomes for PLWH. Future studies should develop various kinds of strategies, which should ensure that the challenges are addressed effectively and efficiently. Future research should also delve into some of the main measures, which can be put in place to ensure that PLWH.

\section{Strength and Limitations}

This review included studies which were carried out in different countries in sub-Saharan Africa. This gives a general picture concerning some of the main nutrition challenges among PLWH in sub-Saharan Africa. The scoping review adopted rigorous and transparent methods. In order to make sure that there was a broad literature search, the search strategy included several electronic bibliographic databases. The articles were thoroughly reviewed to ensure that they met the inclusion criteria. The review might not have identified all the studies in the published and grey literature although attempts were made to be as comprehensive as possible. Additionally, the search was carried out in English terms only. Characterization and interpretation of the included studies were also subject to reviewer bias. 


\section{Conclusions}

The main aim of the study was to explore the nutrition challenges among PLWH in sub-Saharan Africa. Based on the findings of the study, it can be concluded that some of the main nutrition challenges include food insecurity, lack of nutritional support among PLWH, and lack of feeding supplementations.

\section{Funding}

N/A.

\section{Availability of Data and Materials}

All data generated or analysed during this study are presented in this manuscript.

\section{Acknowledgements}

The authors would like to extend their appreciation to Dr. James Noah Ssemanda and Dr. Erigene Rutayisire for review of earlier drafts of this manuscript.

\section{Ethics Approval and Consent to Participate}

Not applicable.

\section{Consent for Publication}

Not applicable.

\section{Competing Interests Statement}

The authors declare that they have no competing interests.

\section{References}

Alebel, A., Wagnew, F., Tesema, C., Kibret, G. D., Petrucka, P., \& Eshite, S. (2018). Effects of undernutrition on survival of human immunodeficiency virus positive children on antiretroviral therapy. Italian journal of pediatrics, 44(1), 29. https://doi.org/10.1186/s13052-018-0472-2

Almeida-Brasil, C. C., Moodie, E. E., McLinden, T., Hamelin, A.-M., Walmsley, S. L., Rourke, S. B., . . Cox, J. (2018). Medication nonadherence, multitablet regimens, and food insecurity are key experiences in the

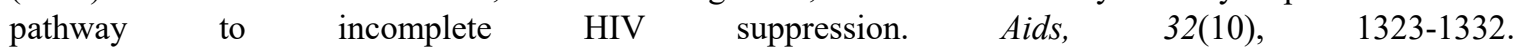
https://doi.org/10.1097/QAD.0000000000001822

Amadi, B., Kelly, P., Mwiya, M., Mulwazi, E., Sianongo, S., Changwe, F., . . Walker-Smith, J. (2001). Intestinal and systemic infection, HIV, and mortality in Zambian children with persistent diarrhea and malnutrition. Journal of pediatric gastroenterology and nutrition, 32(5), 550-554. https://doi.org/10.1097/00005176-200105000-00011

Anema, A., Vogenthaler, N., Frongillo, E. A., Kadiyala, S., \& Weiser, S. D. (2009). Food insecurity and HIV/AIDS: current knowledge, gaps, and research priorities. Current HIV/AIDS Reports, 6(4), 224-231. https://doi.org/10.1007/s11904-009-0030-z

Arksey, H., \& O'Malley, L. (2005). Scoping studies: towards a methodological framework. International journal of social research methodology, 8(1), 19-32. https://doi.org/10.1080/1364557032000119616

Asafo-Agyei, S. B., Antwi, S., \& Nguah, S. B. (2013). HIV infection in severely malnourished children in Kumasi, Ghana: a cross-sectional prospective study. BMC pediatrics, $13(1), 181$. https://doi.org/10.1186/1471-2431-13-181

Badri, M., Maartens, G., Mandalia, S., Bekker, L.-G., Penrod, J. R., Platt, R. W., . . . Beck, E. J. (2005). Cost-effectiveness of highly active antiretroviral therapy in South Africa. PLoS medicine, 3(1), e4. https://doi.org/10.1371/journal.pmed.0030004

Benzekri, N. A., Sambou, J., Diaw, B., Sall, F., Niang, A., Ba, S., . . Seydi, M. (2015). High prevalence of severe food insecurity and malnutrition among HIV-infected adults in Senegal, West Africa. PloS one, 10(11), e0141819. https://doi.org/10.1371/journal.pone.0141819

Berhe, N., Tegabu, D., \& Alemayehu, M. (2013). Effect of nutritional factors on adherence to antiretroviral therapy among HIV-infected adults: a case control study in Northern Ethiopia. BMC Infect Dis, 13, 233. https://doi.org/10.1186/1471-2334-13-233

Bigna, J. J. R., Plottel, C. S., \& Koulla-Shiro, S. (2016). Challenges in initiating antiretroviral therapy for all HIV-infected people regardless of CD4 cell count. Infectious diseases of poverty, 5(1), 85. 
https://doi.org/10.1186/s40249-016-0179-9

Cloete, A., Strebel, A., Simbayi, L., van Wyk, B., Henda, N., \& Nqeketo, A. (2010). Challenges Faced by People Living with HIV/AIDS in Cape Town, South Africa: Issues for Group Risk Reduction Interventions. AIDS research and treatment, 2010, 420270-420270. https://doi.org/10.1155/2010/420270

Duggal, S., Chugh, T. D., \& Duggal, A. K. (2012). HIV and malnutrition: effects on immune system. Clin Dev Immunol, 2012, 784740. https://doi.org/10.1155/2012/784740

Dzinamarira, T., \& Mashora, M. C. I. J. O. C. M. A. P. H. (2019). Synthesizing evidence on nutrition challenges among people living with $\{\mathrm{HIV}\} /\{$ AIDS $\}$ in sub- Saharan Africa: a protocol for a scoping review. International Journal of Community Medicine And Public Health, 6(17), 3173. https://doi.org/10.18203/2394-6040.ijcmph20192871

Elfstrand, L., \& Florén, C.-H. (2010). Management of chronic diarrhea in HIV-infected patients: current treatment options, challenges and future directions. HIV/AIDS (Auckland, N.Z.), 2, 219-224. https://doi.org/10.2147/HIV.S13191

Ensoli, B., Cafaro, A., Monini, P., Marcotullio, S., \& Ensoli, F. (2014). Challenges in HIV Vaccine Research for Treatment and Prevention. Frontiers in immunology, 5, 417-417. https://doi.org/10.3389/fimmu.2014.00417

Evans, D., McNamara, L., Maskew, M., Selibas, K., van Amsterdam, D., Baines, N., . . Sanne, I. (2013). Impact of nutritional supplementation on immune response, body mass index and bioelectrical impedance in HIV-positive patients starting antiretroviral therapy. Nutr $J, \quad 12, \quad 11$. https://doi.org/10.1186/1475-2891-12-111

Gebremichael, D. Y., Hadush, K. T., Kebede, E. M., \& Zegeye, R. T. (2018). Food Insecurity, Nutritional Status, and Factors Associated with Malnutrition among People Living with HIV/AIDS Attending Antiretroviral Therapy at Public Health Facilities in West Shewa Zone, Central Ethiopia. BioMed research international, 2018. https://doi.org/10.1155/2018/1913534

Hailemariam, S., Bune, G. T., \& Ayele, H. T. (2013). Malnutrition: Prevalence and its associated factors in People living with HIV/AIDS, in Dilla University Referral Hospital. Archives of Public Health, 71(1), 13. https://doi.org/10.1186/0778-7367-71-13

Hong, Q. N., Pluye, P., Fàbregues, S., Bartlett, G., Boardman, F., Cargo, M., . . Nicolau, B. (2019). Improving the content validity of the mixed methods appraisal tool: a modified e-Delphi study. Journal of clinical epidemiology, 111, 49-59. e41. https://doi.org/10.1016/j.jclinepi.2019.03.008

Ivers, L. C., Cullen, K. A., Freedberg, K. A., Block, S., Coates, J., Webb, P., \& Mayer, K. H. (2009). HIV/AIDS, undernutrition, and food insecurity. Clinical Infectious Diseases, 49(7), 1096-1102. https://doi.org/10.1086/605573

Jesson, J., Masson, D., Adonon, A., Tran, C., Habarugira, C., Zio, R., . . . Kwayep, R. (2015). Prevalence of malnutrition among HIV-infected children in Central and West-African HIV-care programmes supported by the Growing Up Programme in 2011: a cross-sectional study. BMC Infect Dis, 15(1), 216. https://doi.org/10.1186/s12879-015-0952-6

Kalichman, S. C., Cherry, C., White, D., Kalichman, M. O., Detorio, M. A., Caliendo, A. M., \& Schinazi, R. F. (2012). Use of dietary supplements among people living with HIV/AIDS is associated with vulnerability to medical misinformation on the internet. AIDS research and therapy, $9(1), \quad 1$. https://doi.org/10.1186/1742-6405-9-1

Karim, Q. A. (2017). Current status of the HIV epidemic \& challenges in prevention. The Indian journal of medical research, 146(6), 673. https://doi.org/10.4103/ijmr.IJMR_1912_17

Kharsany, A. B., \& Karim, Q. A. (2016). HIV infection and AIDS in sub-Saharan Africa: current status, challenges and opportunities. The open AIDS journal, 10, 34. https://doi.org/10.2174/1874613601610010034

Loos, J., Nöstlinger, C., Vuylsteke, B., Deblonde, J., Ndungu, M., Kint, I., . . . Laga, M. (2017). First HIV prevalence estimates of a representative sample of adult sub-Saharan African migrants in a European city. Results of a community-based, cross-sectional study in Antwerp, Belgium. PloS one, 12(4), e0174677. https://doi.org/10.1371/journal.pone.0174677

Mbirimtengerenji, N. D. (2007). Is HIV/AIDS epidemic outcome of poverty in sub-saharan Africa? Croatian medical journal, 48(5), 605-617. Retrieved from https://www.ncbi.nlm.nih.gov/pubmed/17948947 
Moramarco, S., Amerio, G., Ciarlantini, C., Chipoma, J., Simpungwe, M., Nielsen-Saines, K., . . Buonomo, E. (2016). Community-based management of child malnutrition in Zambia: HIV/AIDS infection and other risk factors on child survival. International journal of environmental research and public health, 13(7), 666. https://doi.org/10.3390/ijerph13070666

Mothi, S., Karpagam, S., Swamy, V., Mamatha, M. L., \& Sarvode, S. (2011). Paediatric HIV-trends \& challenges. The Indian journal of medical research, 134(6), 912. https://doi.org/10.4103/0971-5916.92636

Moyo, N., Maharaj, P., \& Mambondiani, L. (2017). Food challenges facing people living with HIV/AIDS in Zimbabwe. African Journal of AIDS Research, 16(3), 225-230. https://doi.org/10.2989/16085906.2017.1362018

Penda, C. I., Moukoko, E. C. E., Nolla, N. P., Evindi, N. O. A., \& Ndombo, P. K. (2018). Malnutrition among HIV infected children under 5 years of age at the Laquintinie hospital Douala, Cameroon. The Pan African Medical Journal, 30. https://doi.org/10.11604/pamj.2018.30.91.15832

Pham, M. T., Rajić, A., Greig, J. D., Sargeant, J. M., Papadopoulos, A., \& McEwen, S. A. (2014). A scoping review of scoping reviews: advancing the approach and enhancing the consistency. Research synthesis methods, 5(4), 371-385. https://doi.org/10.1002/jrsm.1123

Poda, G. G., Hsu, C.-Y., \& Chao, J. C. (2017). Malnutrition is associated with HIV infection in children less than 5 years in Bobo-Dioulasso City, Burkina Faso: A case-control study. Medicine, 96(21). https://doi.org/10.1097/MD.0000000000007019

Thapa, R., Amatya, A., Pahari, D. P., Bam, K., \& Newman, M. S. (2015). Nutritional status and its association with quality of life among people living with HIV attending public anti-retroviral therapy sites of Kathmandu Valley, Nepal. AIDS research and therapy, 12, 14-14. https://doi.org/10.1186/s12981-015-0056-9

Thuppal, S. V., Jun, S., Cowan, A., \& Bailey, R. L. (2017). The Nutritional Status of HIV-Infected US Adults. Current developments in nutrition, 1(10), e001636. https://doi.org/10.3945/cdn.117.001636

Trehan, I., O'Hare, B. A., Phiri, A., \& Heikens, G. T. (2012). Challenges in the management of HIV-infected malnourished children in sub-Saharan Africa. AIDS research and treatment, 2012. https://doi.org/10.1155/2012/790786

Weiser, S. D., Fernandes, K. A., Brandson, E. K., Lima, V. D., Anema, A., Bangsberg, D. R., . . Hogg, R. S. (2009). The association between food insecurity and mortality among HIV-infected individuals on HAART. Journal of acquired immune deficiency syndromes (1999), $\quad 52(3), \quad 342$. https://doi.org/10.1097/QAI.0b013e3181b627c2

Weiser, S. D., Young, S. L., Cohen, C. R., Kushel, M. B., Tsai, A. C., Tien, P. C., . . Bangsberg, D. R. (2011). Conceptual framework for understanding the bidirectional links between food insecurity and HIV/AIDS. $\mathrm{Am}$ J Clin Nutr, 94(6), 1729S-1739S. https://doi.org/10.3945/ajen.111.012070

WHO. (2018). Global health observatory data, 2016. Retrieved from https://www.tradingeconomics. $\mathrm{com} /$ ghana/mortality-rate-neonatal-per-1-000-live-births-wb-data.html 


\section{Supplemental File 1 List of full text articles reviewed}

Amadi, B., Mwiya, M., Chomba, E., Thomson, M., Chintu, C., Kelly, P., \& Walker-Smith, J. (2005). Improved nutritional recovery on an elemental diet in Zambian children with persistent diarrhoea and malnutrition. Journal of tropical pediatrics, 51(1), 5-10. https://doi.org/10.1093/tropej/fmh064

Amadi, B., Kelly, P., Mwiya, M., Mulwazi, E., Sianongo, S., Changwe, F., ... \& Chintu, C. (2001). Intestinal and systemic infection, HIV, and mortality in Zambian children with persistent diarrhea and malnutrition. Journal of pediatric gastroenterology and nutrition, 32(5), 550-554. https://doi.org/10.1097/00005176-200105000-00011

Asafo-Agyei, S. B., Antwi, S., \& Nguah, S. B. (2013). HIV infection in severely malnourished children in Kumasi, Ghana: a cross-sectional prospective study. BMC pediatrics, 13(1), 181. https://doi.org/10.1186/1471-2431-13-181

Benzekri, N. A., Sambou, J., Diaw, B., Sall, F., Niang, A., Ba, S., ... \& Gottlieb, G. S. (2015). High prevalence of severe food insecurity and malnutrition among HIV-infected adults in Senegal, West Africa. PloS one, 10(11), e0141819. https://doi.org/10.1371/journal.pone.0141819

Cobb, G., \& Bland, R. M. (2013). Nutritional supplementation: the additional costs of managing children infected with HIV in resource-constrained settings. Tropical Medicine \& International Health, 18(1), 45-52. https://doi.org/10.1111/tmi.12006

Piwoz, E. G., \& Bentley, M. E. (2005). Women's voices, women's choices: the challenge of nutrition and HIV/AIDS. The Journal of nutrition, 135(4), 933-937. https://doi.org/10.1093/jn/135.4.933

Gebremichael, D. Y., Hadush, K. T., Kebede, E. M., \& Zegeye, R. T. (2018). Food Insecurity, Nutritional Status, and Factors Associated with Malnutrition among People Living with HIV/AIDS Attending Antiretroviral Therapy at Public Health Facilities in West Shewa Zone, Central Ethiopia. BioMed research international, 2018. https://doi.org/10.1155/2018/1913534

Jesson, J., \& Leroy, V. (2015). Challenges of malnutrition care among HIV-infected children on antiretroviral treatment in Africa. Medecine et maladies infectieuses, 45(5), 149-156. https://doi.org/10.1016/j.medmal.2015.03.002

Jesson, J., Masson, D., Adonon, A., Tran, C., Habarugira, C., Zio, R., ... \& Sare, E. (2015). Prevalence of malnutrition among HIV-infected children in Central and West-African HIV-care programmes supported by the Growing Up Programme in 2011: a cross-sectional study. BMC infectious diseases, 15(1), 216. https://doi.org/10.1186/s12879-015-0952-6

Miller, C. L., Bangsberg, D. R., Tuller, D. M., Senkungu, J., Kawuma, A., Frongillo, E. A., \& Weiser, S. D. (2011). Food insecurity and sexual risk in an HIV endemic community in Uganda. AIDS and Behavior, 15(7), 1512-1519. https://doi.org/10.1007/s10461-010-9693-0

Moramarco, S., Amerio, G., Ciarlantini, C., Chipoma, J., Simpungwe, M., Nielsen-Saines, K., ... \& Buonomo, E. (2016). Community-based management of child malnutrition in Zambia: HIV/AIDS infection and other risk factors on child survival. International journal of environmental research and public health, 13(7), 666. https://doi.org/10.3390/ijerph13070666

Moyo, N., Maharaj, P., \& Mambondiani, L. (2017). Food challenges facing people living with HIV/AIDS in Zimbabwe. African Journal of AIDS Research, 16(3), 225-230. https://doi.org/10.2989/16085906.2017.1362018

Muenchhoff, M., Healy, M., Singh, R., Roider, J., Groll, A., Kindra, C., ... \& Palma, A. (2018). Malnutrition in HIV-infected children is an indicator of severe disease with an impaired response to antiretroviral therapy. AIDS research and human retroviruses, 34(1), 46-55. https://doi.org/10.1089/aid.2016.0261

Ndeezi, G., Tylleskär, T., Ndugwa, C. M., \& Tumwine, J. K. (2010). Effect of multiple micronutrient supplementation on survival of HIV-infected children in Uganda: a randomized, controlled trial. Journal of the International AIDS Society, 13(1), 18. https://doi.org/10.1186/1758-2652-13-18

Penda, C. I., Moukoko, E. C. E., Nolla, N. P., Evindi, N. O. A., \& Ndombo, P. K. (2018). Malnutrition among HIV infected children under 5 years of age at the Laquintinie hospital Douala, Cameroon. The Pan African Medical Journal, 30. https://doi.org/10.11604/pamj.2018.30.91.15832 
Poda, G. G., Hsu, C. Y., \& Chao, J. C. (2017). Malnutrition is associated with HIV infection in children less than 5 years in Bobo-Dioulasso City, Burkina Faso: A case-control study. Medicine, 96(21). https://doi.org/10.1097/MD.0000000000007019

Sint, T. T., Lovich, R., Hammond, W., Kim, M., Melillo, S., Lu, L., .. \& Heap, A. N. (2013). Challenges in infant and young child nutrition in the context of HIV. AIDS (London, England), 27(02), S169. https://doi.org/10.1097/QAD.0000000000000089

Taye, B., Shiferaw, S., \& Enquselassie, F. (2010). The impact of malnutrition in survival of HIV infected children after initiation of antiretroviral treatment (ART). Ethiopian medical journal, 48(1), 1-10.

Trehan, I., O'Hare, B. A., Phiri, A., \& Heikens, G. T. (2012). Challenges in the management of HIV-infected malnourished children in sub-Saharan Africa. AIDS research and treatment, 2012. https://doi.org/10.1155/2012/790786

\section{Copyrights}

Copyright for this article is retained by the author(s), with first publication rights granted to the journal.

This is an open-access article distributed under the terms and conditions of the Creative Commons Attribution license (http://creativecommons.org/licenses/by/4.0/). 